\title{
Therapeutic effects of pyrrolidine dithiocarbamate on acute lung injury in rabbits
}

Meitang Wang ${ }^{1}$, Tao Liu', Dian Wang ${ }^{2}$, Yonghua Zheng ${ }^{2}$, Xiangdong Wang ${ }^{2^{*}}$ and Jian $\mathrm{He}^{1^{*}}$

\begin{abstract}
Background: Acute lung injury (ALI) and acute respiratory distress syndrome (ARDS) is an early characteristic of multiple organ dysfunction, responsible for high mortality and poor prognosis in patients. The present study aims to evaluate therapeutic effects and mechanisms of pyrrolidine dithiocarbamate (PDTC) on ALI.

Methods: Alveolar-arterial oxygen difference, lung tissue edema and compromise, NF- $\kappa$ B activation in polymorphonuclear neutrophil (PMN), and systemic levels of tumor necrosis factor-alpha (TNFa) and intercellular adhesion molecule-1 (ICAM-1) in rabbits induced by the intravenous administration of lipopolysaccharide (LPS) and treated with PDTC. Production of TNFa and IL-8, activation of Cathepsin G, and PMNs adhesion were also measured.

Results: The intravenous administration of PDTC had partial therapeutic effects on endotoxemia-induced lung tissue edema and damage, neutrophil influx to the lung, alveolar-capillary barrier dysfunction, and high systemic levels of TNFa and ICAM-1 as well as over-activation of NF- $\kappa$ B. PDTC could directly and partially inhibit LPS-induced TNFa hyper-production and over-activities of Cathepsin G. Such inhibitory effects of PDTC were related to the various stimuli and enhanced through combination with PI3K inhibitor.
\end{abstract}

Conclusion: NF- $\kappa$ B signal pathway could be one of targeting molecules and the combination with other signal pathway inhibitors may be an alternative of therapeutic strategies for ALI/ARDS.

Keywords: acute lung injury TNF- $\alpha$ ? $a$ ?, ICAM-1, NF- $\kappa$ ? K?B, pyrrolidine dithiocarbamate

\section{Background}

Acute lung injury (ALI) and acute respiratory distress syndrome (ARDS) is an early characteristic of multiple organ dysfunction, which is responsible for high mortality and poor prognosis in patients with trauma, infection, shock, acute pancreatitis or sepsis [1]. Lipopolysaccharide (LPS) as the bacterial pathogen could trigger the over-production and over-expression of inflammatory mediators, including cytokines, chemokines, adhesion molecules, reactive oxygen species, and reactive nitrogen species [2], Primary and/or secondary excessive production of those mediators could lead to the development of systemic inflammation and lung tissue damage as well as coagulation/anti-coagulation

\footnotetext{
* Correspondence: xiangdong.wang@telia.com; hejiansmmu@126.com ${ }^{1}$ Department of Emergency Medicine, The Second Military University Changhai Hospital, China

${ }^{2}$ Department of Respiratory Medicine and Biomedical Research Center,

Fudan University Zhongshan Hospital, Shanghai, China

Full list of author information is available at the end of the article
}

imbalance, endothelial barrier dysfunction, and multiple organ dysfunction [3]. ALI could result from the activation of cytokine networks and the induction of proinflammatory gene expression, mediated by activating an inducible transcription factor, such as nuclear factor $-\kappa \mathrm{B}$ $(\mathrm{NF}-\kappa \mathrm{B})$, a driving force in the initiation and progression of systemic inflammation, ALI and multiple organ dysfunction $[4,5]$.

The present study is aimed at evaluating the effects of pyrrolidine dithiocarbamate (PDTC), an inhibitor of NF$\kappa \mathrm{B}$, on alveolar-capillary barrier dysfunction, lung tissue edema and compromise, NF- $\kappa \mathrm{B}$ activation in polymorphonuclear neutrophil (PMN), and systemic levels of tumor necrosis factor-alpha (TNF- $\alpha$ ) and intercellular adhesion molecule-1 (ICAM-1) in rabbits induced by the intravenous administration of lipopolysaccharide (LPS). Furthermore, direct effects of PDTC and dexamethasone (DEX) used as reference on PMN activities characterized by the production of TNF- $\alpha$ and cell

\section{Biomed Central}

(c) 2011 Wang et al; licensee BioMed Central Ltd. This is an Open Access article distributed under the terms of the Creative Commons Attribution License (http://creativecommons.org/licenses/by/2.0), which permits unrestricted use, distribution, and reproduction in any medium, provided the original work is properly cited. 
activation of Cathepsin G were also studied. We also investigated the potential variation of PDTC effects on PMNs adhesion after different stimulations with leukotriene-B4 (LTB4), interleukin-8 (IL-8), and LPS and compare the therapeutic effects of the combination of PDTC and wortmannin.

\section{Materials and methods Induction of ALI}

New Zealand rabbits with a mixture of female and male, weighing $2.0 \mathrm{~kg}$, were used. The rabbits were kept in a 12:12-h night-day rhythm, fed with standard chow, and provided water ad libitum. The study was approved by the Animal Care Committee of The Second Military University and performed in accordance with the Guide for the Care and Use of Laboratory Animals. The rabbits were anesthetized with intravenous injection of $20 \%$ urethane at the dose of $5 \mathrm{ml} / \mathrm{Kg}$. The femoral vein and homo-lateral femoral artery were separated, exposed and cannulated with a heparinized pediatric cardiac catheter for fluid replacement, drug delivery and blood sampling, respectively. Endotoxemia-associated ALI was induced by an intravenous injection of LPS (Escherichia coli, O111:B4, L-2630, Sigma Chemical, St. Louis, MO) at the dose of $500 \mu \mathrm{g} / \mathrm{kg}$. Vehicle or PDTC at the dose of 100 $\mathrm{mg} / \mathrm{kg}$ PDTC (Sigma) was intravenously administered one hour after the induction. Ringer's solution was intravenously infused continuously at the speed of $8 \mathrm{ml} /$ $\mathrm{kg} / \mathrm{h}$ during the experiment.

\section{Sampling}

Blood was sampled before LPS injection as $0 \mathrm{~h}$, and then 1, 2, 4 and 6 hours after LPS injection, respectively, for the measurement of arterial blood gas analysis. Blood was collected and centrifuged at $3000 \times \mathrm{g}$ for 5 min and the serum was stored at $-80^{\circ} \mathrm{C}$ for the measurements of TNF- $\alpha$ and ICAM- 1 assay and isolation of PMNs. The same volume of fluid was replaced in all animals after sampling. The superior lobe and inferior part of the right lung was harvested for measurement of dry/wet $(D / W)$ ratio and pathology, respectively. The lung tissue was cleansed of blood and weighed as wet weight, and then kept a $75^{\circ} \mathrm{C}$ for $72 \mathrm{~h}$ for dry weight to calculate the lung $\mathrm{D} / \mathrm{W}$ weight ratio.

\section{Pathological score}

The lung was perfused through the bronchus at $20 \mathrm{cmH}_{2} \mathrm{O}$ and fixed with $10 \%$ formaldehyde solution after the experiment was terminated. The lung tissues were embedded in paraffin wax, stained with hematoxylin and eosin, and examined under a light microscope. The lung injury was scored according to inflammatory changes, hemorrhage of alveoli and interstitial tissue, and pulmonary edema. Each pathological change was scored on a scale from $0-3$ (normal, 0; minimal change, 1; medium change, 2; and severe change, 3 ), as described previously [6].

\section{Alveolar-arterial oxygen difference}

$\mathrm{PaO}_{2}, \mathrm{PaCO}_{2}$, and $\mathrm{pH}$ were measured by blood gas analyzer (ABL 111, Radiometer, Copenhagen, Denmark). $\mathrm{PaO}_{2}$ (alveolar oxygen tension) was calculated by the following equation. $\mathrm{P}_{\mathrm{A}} \mathrm{O}_{2}=($ barometric pressure -47$) \times$ $\mathrm{FiO}_{2}-\mathrm{PaCO}_{2} \mathrm{R}$. R, an exchange ratio, is assumed as 0.8 as described previously [7]. The alveolar-arterial $\mathrm{PO}_{2}$ difference $\left(\mathrm{P}_{\mathrm{A}-\mathrm{a}} \mathrm{O}_{2}\right)=($ barometric pressure -47$) \times \mathrm{FiO}_{2}$ - $\mathrm{PaCO}_{2} \mathrm{R}-\mathrm{PaO}_{2}$. The severity of gas exchange impairment $\left(\mathrm{P}_{\mathrm{A}-\mathrm{a}} \mathrm{O}_{2}\right)$ was examined using the linear correlation coefficient.

\section{PMN isolation}

PMNs were separated as described previously [8]. Briefly, neutrophils were purified under endotoxin-free conditions. Anti-coagulated blood was added to $6 \%$ dextran (mol wt 70,000$)$ in $0.9 \%$ sodium chloride solution in a 3:1 ratio (vol/vol, blood/dextran) and kept at room temperature for $30 \mathrm{~min}$. The leukocytes were aspirated and centrifuged at $1000 \times \mathrm{g}$ for $6 \mathrm{~min}$ and the pellet was then resuspended in $2 \mathrm{ml}$ RPMI 1640 (GIBCO, New York) and underlaid with 42\% Percoll (Pharmacia, New Jersey), followed by 51\% Percoll, and centrifuged for 10 minutes at $275 \times \mathrm{g}$. The cells were then washed twice in RPMI-1640, afterwards the erythrocytes were lysed. The final cell population was $>98 \%$ PMNs by differential staining and $>99 \%$ viable by trypan blue exclusion. Purified neutrophils were resuspended in RPMI 1640 supplemented at a final concentration of $5 \times 10^{6}$ cells $/ \mathrm{ml}$ and incubated in 48-well cell culture plates at $37^{\circ} \mathrm{C}$ in a $5 \% \mathrm{CO}_{2}$ humidified atmosphere.

\section{Nuclear protein extraction}

Nuclear protein was extracted as described previously [4]. Briefly, PMN $\left(5 \times 10^{6}\right)$ were lysed in the buffer containing HEPES (10 mM, pH 7.9), $\mathrm{KCl}(10 \mathrm{mM})$, EDTA $(0.1$ $\mathrm{mM})$, dithiothreitol (1 mM, DTT), and phenylmethylsulfonyl fluoride (1 mM, PMSF). Proteins were protected with $1 \%$ protease inhibitor cocktail, containing antipain, aprotinin and leupeptin ( $500 \mu \mathrm{g}$, respectively), pepstatin $(50 \mu \mathrm{g})$, bestatin $(750 \mu \mathrm{g})$, phosphoramidone $(400 \mu \mathrm{g})$, and trypsin inhibitor $(500 \mu \mathrm{g}$, ROCHE, Mannheim, Germany) in $1 \mathrm{ml}$. The cell suspension was then centrifuged at $12000 \times \mathrm{g}$ for $5 \mathrm{~min}\left(4^{\circ} \mathrm{C}\right)$. The nuclear pellet was resuspended and rocked vigorously for $20 \mathrm{~min}$ and total protein concentration was determined by Bradford assay (Coomassie Plus, Pierce, Rockford, IL, USA).

\section{Electrophoretic mobility shift assay (EMSA)}

Detection of DNA-protein binding by EMSA was done using LightShift chemiluminescent electrophoretic 
mobility shift assay kit (Pierce Biotechnology, Rockford, IL, USA). Binding reactions were performed by adding 2 $\mu \mathrm{g}$ of the nuclear extracts to a mixture containing 40 mol of biotin-labeled, double-stranded probes (5'AGTTGAGGGGACTTTCCCAGGC-3') 7 in $20 \mu \mathrm{l}$ of binding buffer $[10 \mathrm{mM}$ Tris ( $\mathrm{pH} 7.5), 10 \mathrm{mM}$ EDTA, $0.5 \mathrm{mM}$ DTT, $50 \mathrm{mM} \mathrm{NaCl}$, and $5 \%$ glycerol] containing $2 \mu \mathrm{g}$ of poly $(\mathrm{dI}-\mathrm{dC})$ :poly $(\mathrm{dI}-\mathrm{dC})$. For supershift experiments, antibody $(1 \mu \mathrm{g})$ were added to aliquots of extract and incubated for $20 \mathrm{~min}$ on ice before the adding of the reaction mixture. Competition reaction mixtures contained a 100-fold molar excess of non-labeled double-stranded oligoDNAs. The mixtures were then resolved by PAGE and visualized by horseradish peroxidase-conjugated streptavidin.

\section{Measurements of TNF, ICAM-1 and IL-8}

Levels of TNF, ICAM-1 and IL-8 in serum or cell supernatants were determined using enzyme-linked immunosorbent assay (ELISA) in accordance with the protocol provided by the manufacturer (LIFEKEY BioMeditech Co., American). Briefly, primary antibody was plated and incubated at room temperature overnight. Samples were added and incubated for $2 \mathrm{~h}$, the plates were washed, and a biotinylated secondary antibody was added and incubated for $2 \mathrm{~h}$. Plates were washed again, and streptavidin bound to horseradish peroxidase was added for $20 \mathrm{~min}$. After a further wash, tetramethylbenzidine was added for color development, and the reaction was terminated with $2 \mathrm{M} \mathrm{H}_{2} \mathrm{SO}_{4}$. Absorbance was measured at $450 \mathrm{~nm}$.

\section{Cathepsin G activity}

Cathepsin G was isolated and the activity of Cathepsin G was measured as described previously $[9,10]$. In brief, neutrophils were suspended in PBS, sonicated trice and centrifugated at $600 \times \mathrm{g}$ for $10 \mathrm{~min}$. The supernatant was centrifuged at $16,000 \times \mathrm{g}$ for $30 \mathrm{~min}$ and the pellet was resuspended in $1 \mathrm{M} \mathrm{NaCl}$ with $0.005 \%$ Triton $\mathrm{X}$ 100. Proteins were precipitated by ammonium sulfate (60\% saturation) and then resuspended in $40 \mathrm{ml}$ of 0.05 $\mathrm{M}$ Tris- $\mathrm{HCl}$ at $\mathrm{pH}$ 8.0. After the centrifugation, the supernatant was subjected to an elastin-Sepharose affinity chromatography column $(2.5 \times 20 \mathrm{~cm})$ and equilibrated with $0.05 \mathrm{M}$ Tris buffer at $\mathrm{pH}$ 8.0. The part of cathepsin $\mathrm{G}$ was eluted with $1 \mathrm{M} \mathrm{NaCl}$ with $0.05 \mathrm{M} \mathrm{Na}$ acetate and $20 \%$ DMSO at $\mathrm{pH} 5.0$, pooled and dialyzed in Vivaspin cut-off columns (5000 MWCO) in $1 \mathrm{M}$ $\mathrm{NaCl}$ with $20 \mathrm{mM} \mathrm{Na}$ acetate at $\mathrm{pH} 5.5$. It was then subjected to ion-exchange chromatography (CM Sephadex C-50) column and washed thrice, and the bound material was eluted by a linear $\mathrm{NaCl}$ gradient from 0.15 to $1 \mathrm{M} .5 \mathrm{ml}$ was collected at a flow rate of $30 \mathrm{ml} / \mathrm{h}$. Purified enzyme $(0.2 \mu \mathrm{g})$ was diluted in $200 \mu \mathrm{l}$ of
HEPES $0.1 \mathrm{M}, \mathrm{NaCl} 0.5 \mathrm{M}(\mathrm{pH} 7.4)$ and 10\% DMSO, and incubated with N-Suc-Ala-Ala-Pro-Phe-pNA (SucAAPF-pNA, $1 \mathrm{mM}$ ) as substrate. The absorbance was measured at $410 \mathrm{~nm}$ at $25^{\circ} \mathrm{C}$.

\section{PMN adhesion}

Neutrophils from normal rabbits were isolated, purified and cultured. Neutrophil adhesion was measured with a slight modification of the previous demonstration [11]. Cells were labeled with 2', 7'-bis(2-carboxyethyl) -5(6)carboxyfluorescein acethoxymethyl ester (BCECF/AM, $10 \mu \mathrm{g} / \mathrm{mL}$; Sigma, MO) for $30 \mathrm{~min}$ at $37^{\circ} \mathrm{C}$. RPMI- 1640 containing $2 \%$ fetal calf serum was added for the terminal reaction. Human umbilical vein endothelial cells (HUVECs) and endothelial cell growth medium (EGM2, CC3156) were purchased (Clonetics, San Diego, CA), containing $10 \%$ fetal bovine serum, hydrocortisone, hFGF-B, vEGF, R3-IGF-I, ascorbic acid, hEGF, GA-1000, and heparin. HUVECs were cultured in 24-well plates until confluent, at which time different concentrations of SHBM1009 were added and then incubated for an additional 12 hours. KC and LTB4 $(10 \mathrm{ng} / \mathrm{mL})$ was added to the wells and incubated for 24 hours and HUVECs were then co-incubated with $10^{6}$ labeled neutrophils/well for 30 minutes at $37^{\circ} \mathrm{C}$. After removing non-adhering cells and washing and lysing adhering cells, fluorescence was measured with an excitation at $510 \mathrm{~nm}$ and emission at $550 \mathrm{~nm}$. The increasing adhesion rate was calculated with the following formulation: [fluorescence intensity in stimulating cells - fluorescence intensity in non-stimulating cells]/fluorescence intensity in stimulating cells X 100 .

\section{Experimental design}

In order to evaluate the concept of therapeutic effects of NF- $\kappa \mathrm{B}$ inhibitor, 60 rabbits were randomly allocated into three groups $(\mathrm{n}=20): 1)$ animals were challenged and treated with vehicle (Group A), 2) animals were challenged with LPS and treated with vehicle (Group B) and 3) animals were challenged with LPS and treated with PDTC (Group C). The ALI was defined by measuring lung tissue edema (dry/wet weight ratio), lung damage (pathology) and dysfunction $\left(\mathrm{P}_{\mathrm{A}-\mathrm{a}} \mathrm{O}_{2}\right)$. Systemic inflammatory response was monitored by the serum levels of TNF, IL- 8 and ICAM-1, whereas NF- $\kappa$ B involvement was indicated by $\mathrm{PMN} N \mathrm{NF}-\kappa \mathrm{B}$ activities. In order to understand the direct effect of PDTC on PMNs, after the cells reached confluence, PMNs $\left(10^{6}\right)$ were treated with vehicle, PDTC $(100 \mathrm{nM})$ or dexamethesone (DEX) dissolved in dimethyl sulfoxide (final $0.1 \%$ ) for $4 \mathrm{~h}$ in serum-free RPMI medium and challenged with vehicle or LPS at $1 \mu \mathrm{g} / \mathrm{ml}$ for 24 hours.

Dose-associated effects of PDTC on different stimuliinduced PMN activation was monitored by measuring 
PMN adhesion 24 hours after the stimulation with vehicle, LPS, IL-8 and leukotriene B4 (LTB4) at $1 \mu \mathrm{g} / \mathrm{ml}$. In order to evaluate the potential involvement of phosphoinositide 3-kinase (PI3K) in the activity of PMNs, cells were treated with vehicle, wortmannin (WT, a specific, covalent and irreversible inhibitor of the class I, II, and III PI3K members, $100 \mathrm{nM})$, PDTC (100 nM), or combination of WT and PDTC and IL-8 production was measured.

\section{Statistic analysis}

Data were expressed as means \pm standard deviations. The data from female and male rabbits were pooled after there was no statistical significance between them. Groups were compared by Repeated Measures Analysis of Variance and Kruskal-Wallis test. Least Significant Difference (LSD) test and the Nemenyi test were used for comparison between two groups. The statistical analysis was conducted by SAS 9.1.3 software. $P$ value less than 0.05 is considered as significant.

\section{Results}

No animals died before the termination of experiment. The values of $\mathrm{P}_{\mathrm{A}-\mathrm{a}} \mathrm{O}_{2}$ in all animals treated with vehicle or PDTC from 1 hour and onwards after ALI induction were significantly higher, as compared with those treated and challenged with vehicle (Figure $1, \mathrm{p}<0.01$, respectively). Values of ALI animals treated with PDTC were significantly higher than those with vehicle 4 and 6 hours after the administration of LPS $(\mathrm{p}<0.05)$. Pathological alterations of ALI animals treated with vehicle or PDTC were showed in Figure 1. The lungs of animals

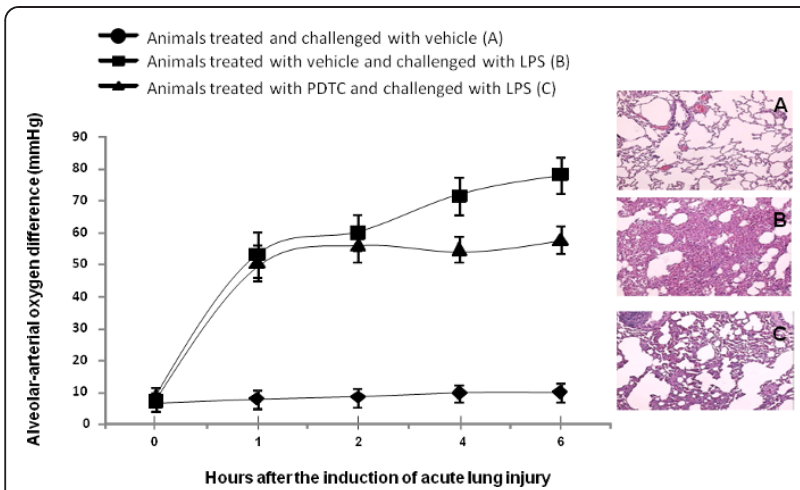

Figure 1 Values of alveolar-capillary oxygen difference in animals. Animals were treated and challenged with vehicle (A), treated with vehicle and challenged with lipopolysaccharide (LPS) (B), or treated with pyrrolidine dithiocarbamate (PDTC) and challenged with LPS (C). Animals were intravenously challenged and treated for 0 (before challenge), 1, 2, 4 and 6 hours and each group had 20 animals. Histological photographs of the lung (hematoxylin \& eosin, X200) 6 hours after the intravenous challenge and treatment. treated with vehicle and challenged with LPS had thicker alveolar wall, infiltration of leukocytes of which more than $90 \%$ were neutrophils, intra-alveolar hemorrhage, formation of micro-thrombosis, alveolar deteleotasis and edematous fluid in alveolar space (Figure 1B). Pathological alterations in the lungs of animals with LPS and PDTC were less severe, including clearer alveolar structure and compromise as well as leukocyte influx (Figure 1C). There were still definite changes when compared with animals treated and challenged with vehicle (Figure 1A).

Values of lung dry/wet weight of animals challenged with LPS and treated with vehicle or PDTC were significantly lower than those challenged and treated with vehicle (Figure $2 \mathrm{~A}, \mathrm{p}<0.01$ or 0.05 , respectively). Animals treated with PDTC had significantly higher levels of lung dry/wet weight than those with vehicle 24 hours after the administration of LPS $(\mathrm{p}<0.05)$. Histological scores of lung pathology in animals challenged with LPS and treated with vehicle or PDTC were significantly higher than those without LPS (Figure 2B, p $<0.01$, respectively).

Serum levels of TNF $\alpha$ significantly increased in animals treated with vehicle or PDTC from 1 hour after LPS injection, as compared to those challenged with vehicle (Figure $3 \mathrm{~A}, \mathrm{p}<0.01$, respectively). Animals

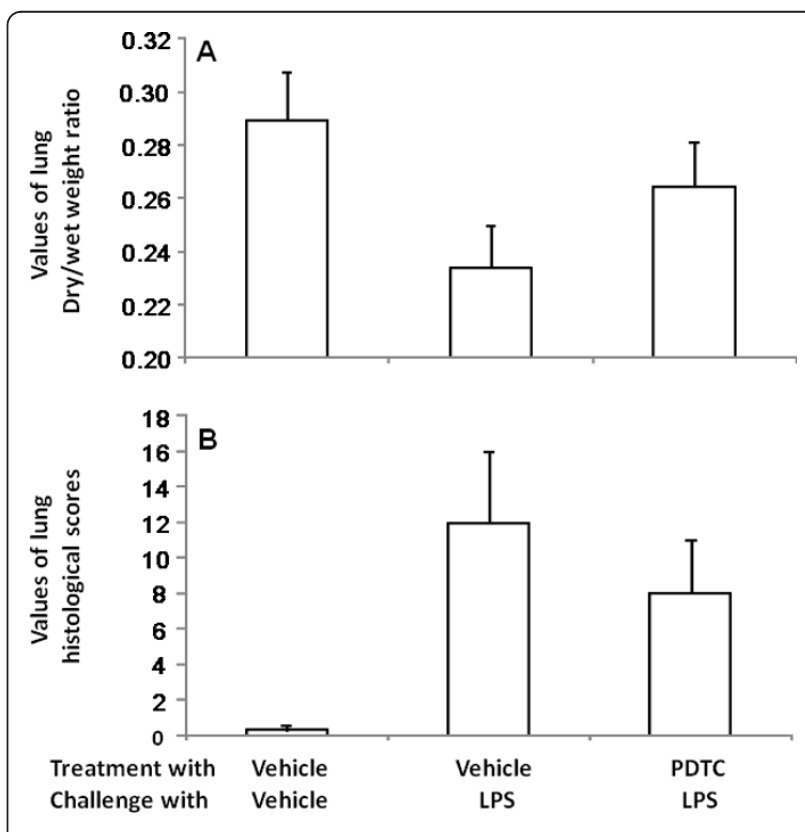

Figure 2 Values of dry/wet lung weight and histological score in animals. Animals were treated and challenged with vehicle (A), treated with vehicle and challenged with lipopolysaccharide (LPS) (B), or treated with pyrrolidine dithiocarbamate (PDTC) and challenged with LPS (C). Animals were intravenously challenged and treated for 0 (before challenge), 1, 2, 4 and 6 hours and each group had 20 animals. 


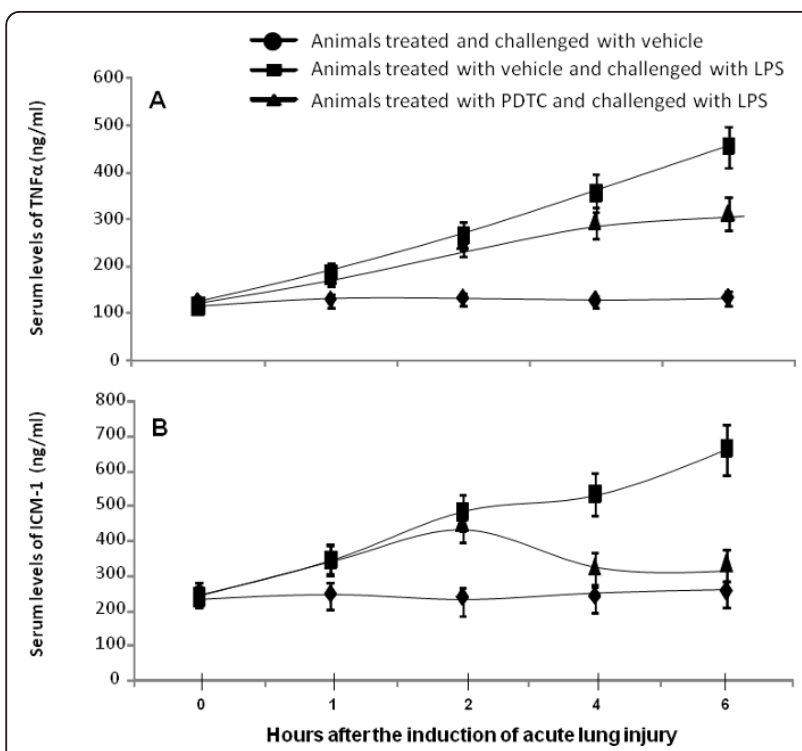

Figure 3 Serum levels of tumor necrosis factor-alpha (TNF- $\alpha$ ) and intercellular adhesion molecule-1 (ICAM-1) in animals. Animals were treated and challenged with vehicle (A), treated with vehicle and challenged with lipopolysaccharide (LPS) (B), or treated with pyrrolidine dithiocarbamate (PDTC) and challenged with LPS

(C). Animals were intravenously challenged and treated for 0 (before challenge), 1, 2, 4 and 6 hours and each group had 20 animals.

treated with PDTC had significantly lower serum levels of TNF $\alpha$ than those with vehicle 4 and 6 hours after LPS challenge $(p<0.05)$. Serum levels of ICAM-1 in animals treated with vehicle were significantly higher than both those with PDTC 4 and 6 hours after LPS challenge or those challenged and treated with vehicle (Figure 3B, $\mathrm{p}<0.01$, respectively). However, animals challenged with LPS and treated with vehicle or PDTC has significantly higher levels of ICAM-1 than those treated and challenged with vehicle at 1 and 2 hours ( $\mathrm{p}$ $<0.05$ ).

Fig 4 demonstrates the ratio of NF- $\kappa \mathrm{B}$ activity between the densities of each measurement with the mean value at 0 hour and representative results of EMSA analyses of NF- $\kappa$ B activation in PMNs (Figure $4 \mathrm{~A}-\mathrm{C})$. NF- $\kappa \mathrm{B}$ activity in PMNs from animals treated with vehicle significantly increased from 1 after LPS challenge, as compared with those treated with PDTC or without LPS ( $\mathrm{p}<0.05$ or 0.01 , respectively). There was no statistical difference of NF- $\kappa \mathrm{B}$ activity between animals with LPS and PDTC or without LPS, except for that at post-challenge 4 hours $(\mathrm{p}<0.05$, Figure 4$)$.

In order to evaluate direct effects of LPS on PMNs, PMNs were stimulated directly by LPS during cell culture and activities of PMNs were indicated by production of TNF $\alpha$ and cathepsin G. The production of TNF $\alpha$ from LPS-stimulated cells treated with vehicle, PDTC or DEX significantly increased with time, as

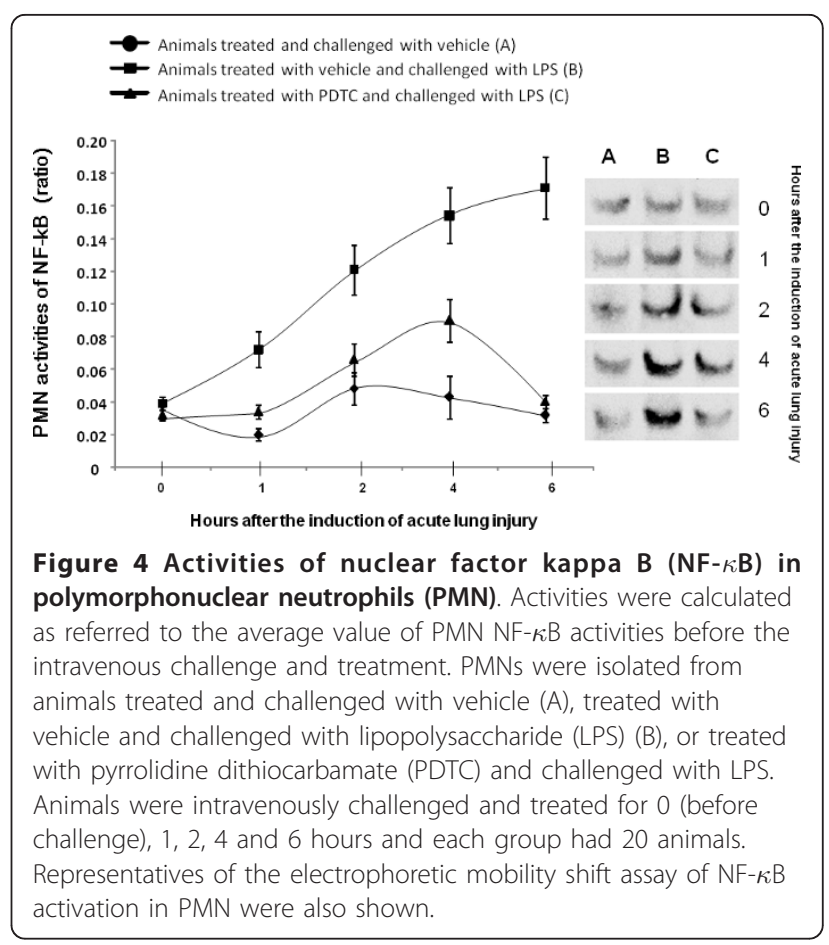

compared with those without LPS (Figure 5A, p $<0.05$ or 0.01 , respectively). Levels of TNF $\alpha$ from LPS-stimulated PMNs treated with PDTC or DEX were significantly lower than those treated with vehicle $(\mathrm{p}<0.05$ or 0.01 , respectively). There was also significant difference between LPS-stimulated cells with PDTC or DEX ( $\mathrm{p}<$

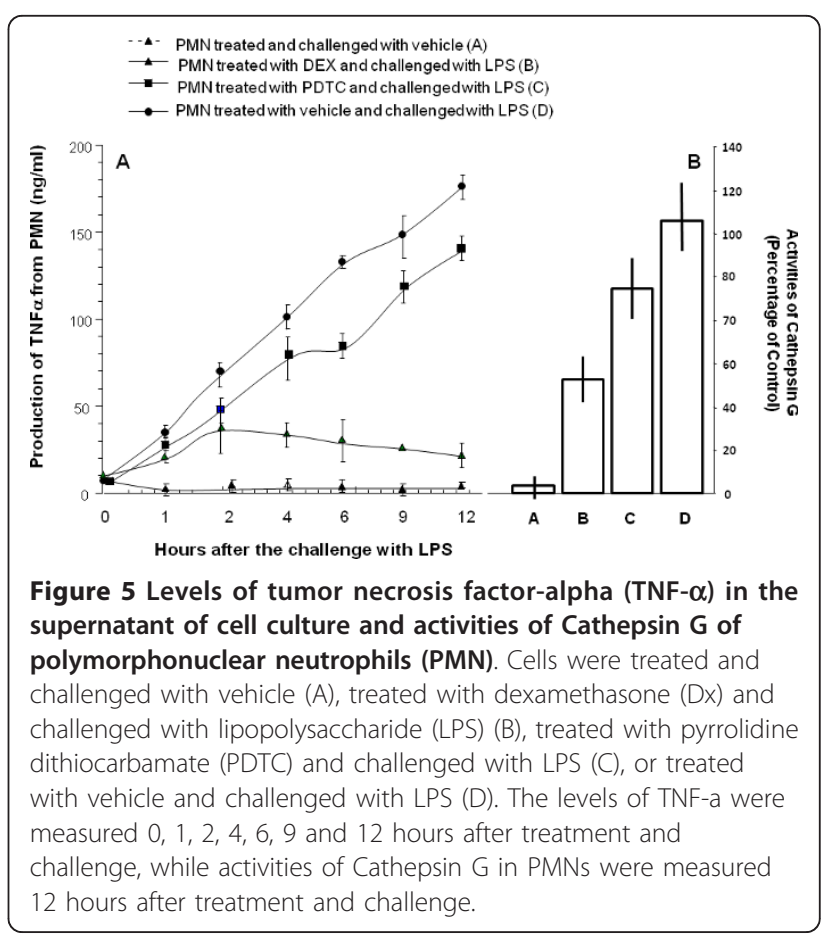


0.05 or 0.01 , respectively). LPS-stimulated cells had significantly higher activity of Cathepsin G than cells with LPS, while PDTC and DEX significantly reduced LPSinduced over-activity and DEX showed even better results than PDTC ( $<<0.05$, respectively, Figure 5B).

PDTC showed significant inhibitory effects on PMN adhesion induced by LTB4, IL8 and LPS at different doses, as shown in Figure 6A. Of them, LTB4-stimulated cell adhesion was more sensitive to PDTC than IL-8 and LPS, and IL-8-stimulated adhesion was more sensitive than LPS did $(p<0.05)$. Cells treated with WT or PDTC had significantly lower IL-8 production than those with vehicle after LPS challenge (Figure 6B, p < 0.05 or 0.01 , respectively), even though those productions were still significantly higher than cells without LPS challenge ( $<<0.01$, respectively). The production of IL-8 from cells treated with the combination of WT and PDTC was significantly lower than that from cells with WT or PDTC alone ( $<0.01$, respectively).

\section{Discussion}

Endotoxemia often happens due to the primary infection or secondary gut origin sepsis [12-15], leading to the development of ALI in the early stage of diseases [16-18]. Multiple intracellular signal pathways, cellular receptors, inflammatory mediators, cells and systems have been suggested as contributors to the pathogenesis of ALI/ARDS. Of them, NF- $\kappa \mathrm{B}$ was proposed to be the central and critical factor, regulating the production of inflammatory mediators [18]. NF- $\kappa$ B inhibitor could attenuate endotoxin-induced ALI [19]. Most of those

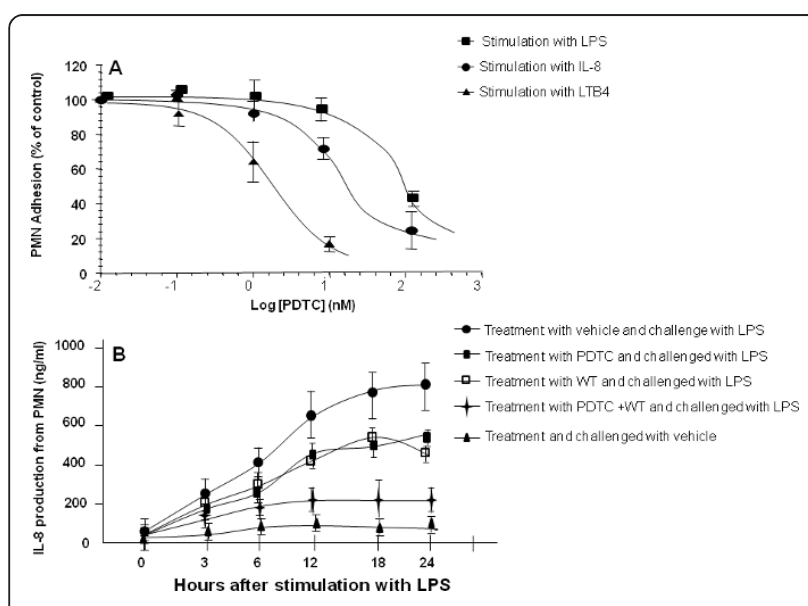

Figure 6 The adhesion of polymorphonuclear neutrophils (PMN). The adhesion was measured 24 hours after treatment with pyrrolidine dithiocarbamate (PDTC) at different concentrations and challenges with leukotriene B4 (LTB4), interleukin-8 (IL-8) and lipopolysaccharide (LPS). Levels of IL-8 in the supernatant of PMN culture were measured $0,3,6,9,12,18$ and 24 hours after the challenge with LPS or vehicle and treatment with vehicle, PDTC alone, wortmannin (WT) alone or the combination of PDTC and WT. investigations were performed in mice and rats, which have their own advantages and limits, especially for the evaluation of drug efficacy [2]. The present study was performed in rabbits and found that PDTC had partial therapeutic effects on endotoxemia-induced ALI.

Those partial effects of PDTC included were found on endotoxemia- induced dysfunction of oxygen exchange between alveolar-capillary barrier, neutrophil influx to lung tissue, and lung edema and damage. The reason why our data did not show the fully inhibitory effects of PDTC on ALI as others found $[19,20]$ may be due to that PDTC was administered after LPS challenge as the therapeutic process to mimic the situation in clinic. It is also possible that PDTC has different effects between small and large animals, or that the severity of ALI in our model was more serious. Endotoxins trigger the production of inflammatory cytokines, responsible for lung compromise and multiple organ failure [21]. Our results demonstrated that PDTC could partially inhibit the production of TNF- $\alpha$ while having more effects on the production of ICAM-1, even though both may play critical roles in endotoxin-induced inflammatory response [22] and were considered as markers of NF- $\kappa \mathrm{B}$ activation [19]. However, the previous study demonstrated that the pretreatment with PDTC did not affect TNF- $\alpha$ production in bronchoalveolar lavage fluid, mRNA expression of TNF- $\alpha$ and ICAM-1 in the lung tissue or NF- $\kappa \mathrm{B}$ activation in macrophages and neutrophil oxidant production [19].

Neutrophils and their production of inflammatory cytokines, oxygen free radicals, and enzymes together play the important role in the pathogenesis of ALI. Our previous studies showed that neutrophils made up more than $95 \%$ of total leukocytes infiltrated into either the lung tissue or alveolar space in mice with LPS-induced ALI [23]. In the present study, we also noticed that the neutrophil influx into the lung tissue increased in rabbits with endotoxemia-induced ALI, while being partially inhibited by PDTC. However, other studies demonstrated that PDTC prevented primary or secondary ALI induced by LPS or mesenteric ischemia/reperfusion probably due to the inhibitory effects on lung lipid peroxidation, malondialdehyde, glutathione, and nitric oxide, rather than the reduction of pulmonary neutrophil sequestration and oxidant production $[19,24]$. Our study showed evidence that PDTC could directly inhibit the activation of PMNs characterized by the production of TNF- $\alpha$ and the activity of Cathepsin G.

Inhibitory effects of PDTC were dependent upon the stimuli, supported by the fact that LPS-stimulated cell adhesion had less sensitive to PDTC than LTB4 and IL8. LTB4 induced a rapid but transient adhesion of PMN to an albumin-coated plastic surface and to cultured human umbilical vein endothelial cells associated with 
leukocyte adhesion protein CD18 [25]. IL-8 is one of the most chemoattractant factors causing PMN adhesion and migration, probably through the phosphorylation and translocation of cytosolic gIVaPLA2 to the nucleus, change in cell shape, polymerization of F-actin, tyrosine phosphorylation as well as enzymatic activity of prolinerich tyrosine kinase 2, a non-receptor protein tyrosine kinase $[26,27]$. The PMN response to LPS was less sensitive in the absence of serum, since LPS stimulated neutrophils by interacting with specific cellular receptors, although upregulation of $\mathrm{CD} 11 \mathrm{~b} / \mathrm{CD} 18$ could still be seen using higher concentrations of LPS [28]. Our data also indicate that LPL-stimulated response had less sensitivity to PDTC which may contribute to the partial inhibitory effects of PDCT.

Activities of NF- $\kappa$ B were increased and associated with the levels of inflammatory mediators in BAL fluid from patients with ARDS $[29,30]$. In addition, NF- $\kappa$ B activation has been identified in alveolar macrophages from humans with ARDS [31]. Endotoxins can activate NF- $\kappa$ B and then initiate transcription and interpretation of many cytokine genes $[32,33]$ closely related with inflammation and immune reaction. NF- $\kappa$ B plays a critical role in the transcriptional activation of multiple genes that contributed to the development of ALI [34]. The present study showed that NF- $\kappa$ B activity in PMNs increased, accompanied with elevated levels of TNF- $\alpha$ and ICAM-1 in the early stage of ALI, while PDTC could reduce LPSinduced over-activation of NF- $\kappa$ B. Although it should be stated that PDTC has been considered as the NF- $\kappa$ B inhibitor, but it also has another multitude of effects, e.g. antioxidant [19,35]. For example, the protective effects of PDTC on LPS-induced ALI was proposed to be associated with antioxidant rather than NF- $\kappa \mathrm{B}$ activity, since pre-treatment with PDTC failed to reduce on LPSinduced NF- $\kappa$ B DNA binding activity in macrophage nuclear extracts [19]. The present study showed the therapeutic effects of PDTC on over-activation of NF- $\kappa$ B in neutrophils. However, the down-regulated activities of $\mathrm{NF}-\kappa \mathrm{B}$ did not show a clear correlation and consistency with the therapeutic effects of PDTC on systemic levels of TNF- $\alpha$, lung tissue edema and damage, and lung dysfunction induced by LPS.

It was hypothesized that PDTC may interfere with NF- $\kappa$ B DNA binding activity through phorbol ester 12 O-tetradecanoylphorbol-13-acetate (TPA) or TNF- $\alpha$-stimulated signaling pathway. PDTC did not inhibit TNF$\alpha$-induced NF-kappaB DNA binding activity but potentiated the effect of TNF- $\alpha$ on kappaB-dependent gene expression. PDTC could induce AP-1 DNA binding and AP-1 reporter gene activity, leading to the inhibition of NF- $\kappa$ B activity [36]. TPA-induced signaling pathway includes the activation of extracellular signal-regulated kinase $1 / 2$, p38 mitogen-activated protein kinase
(MAPK), and PI3K/Akt, which are upstream of NF $\kappa \mathrm{B}$. Our data showed that the combination of PDTC with PI3K inhibitor Wortmannin had more inhibitory effects on LPS-induced PMN overproduction of IL-8, than either on its own. Wortmannin is a specific, covalent inhibitor of PI3Ks, for the class I, II, and III PI3K members, although it can also inhibit other PI3K-related enzymes such as mTOR, DNA-PK, some PI4Ks, myosin light chain kinase, members of the polo-like kinase family and MAPK $[37,38]$. It indicates that multiple signaling pathways associated PI3K-NF- $\kappa$ B communication may be involved in the hyper-activation of PMNs and endotoxemia-induced ALI. This was also supported by the finding that inhibitory effects of DEX on LPSinduced TNF- $\alpha$ production and Cathepsin G over-activation were significantly better than PDTC. It seems that the inhibitory effects of PDTC were not only dependent upon the variation of stimuli and severities of the disease, but also different between targeting cells. For example, effects of PDTC on macrophages might be related with the antioxidant process rather than TNF- $\alpha$ and NF- $\kappa$ B [19], but not on the epithelial cells [39]. However, this is the preliminary study to evaluate PDTC effects in large animals, so it would be important to show the dose-dependent efficacy of PDTC and additional target-specific inhibitors, even though it may be difficult to be found for rabbits. It is also more helpful if the study could measure the recruitment of leukocytes from the circulation to the interstitial tissue and alveolar space. The use together with blocking a PI3K imply potential effect in a multimodal therapeutic setting, which should be further explored due to the complexity of mechanisms involved in ALI.

\section{Conclusion}

The present study demonstrated that the intravenous administration of PDTC had partial therapeutic effects on endotoxemia-induced lung tissue edema and damage, neutrophil influx to the lung, alveolar-capillary barrier dysfunction, and high systemic levels of TNF- $\alpha$ and ICAM-1 as well as over-activation of NF- $\kappa$ B. PDTC could directly and partially inhibit LPS-induced TNF- $\alpha$ hyper-production and over-activities of Cathepsin G. Such inhibitory effects of PDTC were related to the various stimuli and enhanced through combination with PI3K inhibitor. Thus, our data indicate that NF- $\kappa$ B signal pathway may be one of the molecules to target and the combination with other signal pathway inhibitors may be an alternative of therapeutic strategies for ALI/ ARDS.

\section{Contributions}

MTW: performing the study and data analysis and writing manuscript 
TL: making study plan and performing the study anddata analysis

DW: make study plan and performing study, as well as editing manuscript

YHZ: performing study and editing manuscript

XDW: making study plan and advising data analysis as well as writing manuscript

$\mathrm{JH}$ : making study plan and advising data analysis as well as writing manuscript

All authors read and approved the final manuscript

\section{Acknowledgements}

The study was sponsored by the grants from the Shanghai Municipal Health Bureau (08GWQ028 and 08GWD025) and the Science and Technology Commission of Shanghai Municipality (08PJ1402900, 08DZ2293104 and 09540702600), Fudan University and Zhongshan Hospital Grant for Distinguished Professor, and Shanghai Leading Academic Discipline Project (T0206, B115)

\section{Author details}

'Department of Emergency Medicine, The Second Military University Changhai Hospital, China. ${ }^{2}$ Department of Respiratory Medicine and Biomedical Research Center, Fudan University Zhongshan Hospital, Shanghai, China.

\section{Competing interests}

The authors declare that they have no competing interests.

Received: 29 January 2011 Accepted: 13 May 2011

Published: 13 May 2011

\section{References}

1. Matthay MA, Zimmerman GA: Acute lung injury and the acute respiratory distress syndrome: four decades of inquiry into pathogenesis and rational management. Am J Respir Cell Mol Biol 2005, 33:319-327.

2. Chen $H$, Bai C, Wang X: The value of the lipopolysaccharide-induced acute lung injury model in respiratory medicine. Expert Rev Respir Med 2010, 4:773-83.

3. Deng XM, Wang XD, Lasson $\AA$, Sun ZW, Soltesz V, Andersson R: The involvement of multiple protease-antiprotease systems and gut origin sepsis in zymosan-associated endothelial barrier injury and multiple organ dysfunction in rats. Shock 2001, 16:298-303.

4. Liu SF, Malik AB: NF-KB activation as a pathologic mechanism of septic shock and inflammation. Am J Physiol Lung Cell Mol Physiol 2006, 290: L622-L645.

5. Everhart MB, Han W, Sherrill TP, et al: Duration and Intensity of NF-кB Activity Determine the Severity of Endotoxin-Induced Acute Lung Injury. J Immunol 2006, 176:4995-5005

6. Nishina K, Mikawa K, Takao Y, Maekawa N, Shiga M, Obara H: ONO-5046, an elastase inhibitor, attenuates endotoxin-induced acute lung injury in rabbits. Anesth Analg 1997, 84:1097-1103.

7. Chang SC, Chang HI, Shiao GM, Perng RP: Effect of body position on gas exchange in patients with unilateral central airway lesions. Down with the good lung? Chest 1993, 103:787-791.

8. Wang M, He J, Mei B, Ma X, Huo Z: Therapeutic effects and antiinflammatory mechanisms of heparin on acute lung injury in rabbits. Acad Emerg Med 2008, 15:656-63.

9. Tausch L, Henkel A, Siemoneit U, Poeckel D, Kather N, Franke L, Hofmann B, Schneider G, Angioni C, Geisslinger G, Skarke C, Holtmeier W, Beckhaus T, Karas M, Jauch J, Werz O: Identification of human cathepsin $\mathrm{G}$ as a functional target of boswellic acids from the anti-inflammatory remedy frankincense. J Immunol 2009, 183:3433-42.

10. Attucci S, Korkmaz B, Juliano L, Hazouard E, Girardin C, Brillard-Bourdet M, Réhault S, Anthonioz P, Gauthier F: Measurement of free and membranebound cathepsin $G$ in human neutrophils using new sensitive fluorogenic substrates. Biochem J 2002, 366:965-70.
11. Weber C, Erl W, Pietsch A, Weber PC: Aspirin inhibits nuclear factor-kappa $B$ mobilization and monocyte adhesion in stimulated human endothelial cells. Circulation 1995, 91:1914-1917.

12. Wang $X D$, Andersson $R$, Soltesz $V$, Bengmark S: Bacterial translocation after major hepatectomy in patients and rats. Arch Surg 1992, 127:1101-1106.

13. Wang XD, Andersson R, Soltesz V, Guo W, Bengmark S: Water-soluble ethylhydroxyethyl cellulose prevents bacterial translocation induced by major liver resection in the rat. Ann Surg 1993, 217:155-167.

14. Andersson $R$, Wang XD, Sun ZW, Deng XM, Soltesz $V$, Ihse I: The effect of a platelet-activating factor antagonist on pancreatitis-associated gut barrier dysfunction in rats. Pancreas 1998, 17:107-119.

15. Deng XM, Wang XD, Andersson R: Endothelial barrier resistance in multiple organs after septic and non-septic challenges in the rat. J App Physiol 1995, 78:2052-2061

16. Wang XD, Zhao X, Shi CB, Börjesson A, Chen Z, Axelsson J, Zhao H, Andersson R: Potential mechanisms and significance of acute pancreatitis-associated liver injury. Scand J Gastroenterol 2006, 41:604-13.

17. Deng XM, Wang XD, Lasson $\AA$, Sun ZW, Soltesz V, Andersson R: The involvement of multiple protease-antiprotease systems and gut origin sepsis in zymosan-associated endothelial barrier injury and multiple organ dysfunction in rats. Shock 2001, 16:298-303.

18. Tanaka S, Nishiumi S, Nishida M, Mizushina Y, Kobayashi K, Masuda A, Fujita T, Morita Y, Mizuno S, Kutsumi H, Azuma T, Yoshida M: Vitamin K3 attenuates lipopolysaccharide-induced acute lung injury through inhibition of nuclear factor-kappaB activation. Clin Exp Immunol 2010, 160:283-92.

19. Nathens AB, Bitar R, Davreux C, Bujard M, Marshall JC, Dackiw AP, Watson RW, Rotstein OD: Pyrrolidine dithiocarbamate attenuates endotoxin-induced acute lung injury. Am J Respir Cell Mol Biol 1997, 17:608-16

20. Kan SH, Huang F, Tang J, Gao Y, Yu CL: Role of intrapulmonary expression of inducible nitric oxide synthase gene and nuclear factor kappaB activation in severe pancreatitis-associated lung injury. Inflammation 2010, 33:287-94.

21. Zeni F, Freeman B, Natanson C: Anti-inflammatory therapies to treat sepsis and septic shock: a reassessment. Crit Care Med 1997, 25:1095-1100.

22. Christman JW, Holden EP, Blackwell TS: Strategies for blocking the systemic effects of cytokines in the sepsis syndrome. Crit Care Med 1995, 23:955-963.

23. Wang XD, Wang Y, Zhao X, Andersson R, Song Z, Yang D: Potential effects of peroxisome proliferator-activated receptor activator on LPS-induced lung injury in rats. Pulm Pharmacol Ther 2009, 22:318-25.

24. Kabay B, Teke Z, Aytekin FO, Yenisey C, Bir F, Sacar M, Erdem E, Ozden A: Pyrrolidine dithiocarbamate reduces lung injury caused by mesenteric ischemia/reperfusion in a rat model. World J Surg 2007, 31:1707-15.

25. Lindström $P$, Lerner $R$, Palmblad J, Patarroyo M: Rapid adhesive responses of endothelial cells and of neutrophils induced by leukotriene B4 are mediated by leucocytic adhesion protein CD18. Scand J Immunol 1990, 31:737-44

26. Meliton AY, Muñoz NM, Meliton LN, Binder DC, Osan CM, Zhu X, Dudek SM, Leff AR: Cytosolic group IVa phospholipase A2 mediates IL-8/CXCL8induced transmigration of human polymorphonuclear leukocytes in vitro. J Inflamm (Lond) 2010, 18(7):14.

27. Di Cioccio V, Strippoli R, Bizzarri C, Troiani G, Cervellera MN, Gloaguen I, Colagrande A, Cattozzo EM, Pagliei S, Santoni A, Colotta F, Mainiero F, Bertini R: Key role of proline-rich tyrosine kinase 2 in interleukin-8 (CXCL8/IL-8)-mediated human neutrophil chemotaxis. Immunology 2004, 111:407-15.

28. Lynn WA, Raetz CR, Qureshi N, Golenbock DT: Lipopolysaccharide-induced stimulation of $C D 11 \mathrm{~b} / \mathrm{CD} 18$ expression on neutrophils. Evidence of specific receptor-based response and inhibition by lipid A-based antagonists. J Immunol 1991, 147:3072-9.

29. Ware LB, Matthay MA: The acute respiratory distress syndrome. N Engl J Med 2000, 342:1334-1349.

30. Bhatia M, Moochhala S: Role of inflammatory mediators in the pathophysiology of acute respiratory distress syndrome. J Pathol 2004, 202:145-156.

31. Schwartz MD, Moore EE, Moore FA, Shenkar R, Moine P, Haenel JB, Abraham E: Nuclear factor- B is activated in alveolar macrophages from 
patients with acute respiratory distress syndrome. Crit Care Med 1996, 24:1285-1292.

32. Tyrrell DJ, Horne AP, Holme KR, Preuss JM, Page CP: Heparin in inflammation: potential therapeutic applications beyond anticoagulation. Adv Pharmacol 1999, 46:151-208.

33. Farrokhnia N, Roos MW, Terént A, Lennmyr F: Differential early mitogenactivated protein kinase activation in hyperglycemic ischemic brain injury in the rat. Eur J Clin Invest 2005, 35:457-463.

34. Everhart MB, Han W, Sherrill TP, Arutiunov M, Polosukhin W, Burke JR, Sadikot RT, Christman JW, Yull FE, Blackwell TS: Duration and intensity of NF-kappaB activity determine the severity of endotoxin-induced acute lung injury. J Immunol 2006, 176:4995-5005.

35. De Rosa S, Cirillo P, Paglia A, Sasso L, Di Palma V, Chiariello M: Reactive oxygen species and antioxidants in the pathophysiology of cardiovascular disease: does the actual knowledge justify a clinical approach? Curr Vasc Pharmacol 2010, 8:259-75.

36. Watanabe K, Kazakova I, Furniss M, Miller SC: Dual activity of pyrrolidine dithiocarbamate on kappaB-dependent gene expression in U937 c. Cell Signal 1999, 11:371-83.

37. Vanhaesebroeck B, Leevers SJ, Ahmadi K, Timms J, Katso R, Driscoll PC, Woscholski R, Parker PJ, Waterfield MD: Synthesis and function of 3phosphorylated inositol lipids. Annu Rev Biochem 2001, 70:535-602.

38. Liu Y, Jiang N, Wu J, Dai W, Rosenblum JS: Polo-like kinases inhibited by wortmannin. Labeling site and downstream effects. J Biol Chem 2007, 282:2505-11.

39. Sunil Y, Ramadori G, Raddatzc D: Influence of NFkappaB inhibitors on IL1 beta-induced chemokine CXCL8 and -10 expression levels in intestinal epithelial cell lines: glucocorticoid ineffectiveness and paradoxical effect of PDTC. Int J Colorectal Dis 2010, 25:323-33.

doi:10.1186/1479-5876-9-61

Cite this article as: Wang et al: Therapeutic effects of pyrrolidine dithiocarbamate on acute lung injury in rabbits. Journal of Translational Medicine 2011 9:61.

\section{Submit your next manuscript to BioMed Central and take full advantage of:}

- Convenient online submission

- Thorough peer review

- No space constraints or color figure charges

- Immediate publication on acceptance

- Inclusion in PubMed, CAS, Scopus and Google Scholar

- Research which is freely available for redistribution

Submit your manuscript at www.biomedcentral.com/submit 